\title{
Erratum to: T-Cell Trafficking and Anti-Adhesion Strategies in Inflammatory Bowel Disease: Current and Future Prospects
}

\author{
Mahmoud H. Mosli • Jesus Rivera-Nieves • \\ Brian G. Feagan
}

Published online: 19 February 2014

(c) Springer International Publishing Switzerland 2014

\section{Erratum to: Drugs}

DOI 10.1007/s40265-013-0176-2

Section 3.1.6.1 Efalizumab. Last sentence, which previously read:

However, the development of PML in three etrolizumabtreated patients with psoriasis resulted in the drug being withdrawn from the market in 2009.

Should read:

However, the development of PML in three efalizumabtreated patients with psoriasis resulted in the drug being withdrawn from the market in 2009.

The online version of the original article can be found under doi:10.1007/s40265-013-0176-2.

M. H. Mosli · B. G. Feagan ( $₫)$

Department of Medicine, University of Western Ontario,

100 Perth Dr, London, ON N6A 5K8, Canada

e-mail: Brian.Feagan@RobartsInc.com

\section{H. Mosli}

Department of Medicine, King Abdulaziz University,

Jeddah, Saudi Arabia

M. H. Mosli · B. G. Feagan

Robarts Clinical Trials Inc, Robarts Research Institute,

University of Western Ontario, 100 Perth Dr, London,

ON N6A 5K8, Canada

J. Rivera-Nieves

Department of Medicine, Division of Gastroenterology, Inflammatory Bowel Disease Center, University of California,

San Diego, USA 